\title{
Effect of Temperature on Corrosion Behavior of VM110SS Casing Steel in the $\mathrm{CO}_{2} / \mathrm{H}_{2} \mathrm{~S}$ Coexistent Environment
}

\author{
Naiyan Zhang ${ }^{1}$, Dezhi Zeng ${ }^{1, *}$, Zhiming $\mathrm{Yu}^{1}$, Wentao Zhao ${ }^{2}$, Junying $\mathrm{Hu}^{1}$, Wenliang Deng ${ }^{3}$, Gang Tian ${ }^{4}$ \\ ${ }^{1}$ State Key Laboratory of Oil \& Gas Reservoir Geology and Exploitation, Southwest Petroleum \\ University, Chengdu 610500, China; \\ ${ }^{2}$ PetroChina Southwest Oil and Gas Field Company, Luzhou 646000, China \\ ${ }^{3}$ China Petroleum Pipeline Engineering Co., Ltd, Langfang 065000, China \\ "E-mail: swpuzny@163.com
}

doi: $10.20964 / 2018.05 .36$

Received: 14 December 2017 / Accepted: 28 February 2018 / Published: 10 April 2018

\begin{abstract}
The effect of temperature on the corrosion behavior of VM110SS casing steel in a $\mathrm{H}_{2} \mathrm{~S} / \mathrm{CO}_{2}$ coexisting environment was investigated by high temperature and high pressure (HTHP) autoclave and the electrochemical corrosion method. In addition, scanning electron microscopy (SEM) and energy dispersive spectrometry (EDS) were used to characterize the morphologies and structure of the corrosion scales. The results show that the corrosion rates of VM110SS steel in the gas-liquid two phase acidic environment exponentially increase in the initial stage and then decrease with the rise in temperature, and the corrosion rate reaches the peak at $90^{\circ} \mathrm{C}$. The principal components of the product may be $\mathrm{Fe}_{\mathrm{x}} \mathrm{S}_{\mathrm{y}}$, indicating that the corrosion process is mainly dominated by $\mathrm{H}_{2} \mathrm{~S}$. The corrosion scales with a porous flocculent structure can be detected in the gas phase; however, the corrosion scale with a brittle characteristic can be easily exfoliated in the liquid phase. Electrochemical tests show that the corrosion current density of VM110SS steel increases with the increase of temperature, and the total impedance decreases. The cathode process is greatly affected by temperature, and the corrosion reaction is mainly controlled by diffusion and activation. The investigation provides a theoretical basis for corrosion failure analysis of casing and technical guidance for material selection.
\end{abstract}

Keywords: $\mathrm{H}_{2} \mathrm{~S} / \mathrm{CO}_{2}$; VM110SS steel; temperature; corrosion scales; electrochemistry

\section{FULL TEXT}

(C) 2018 The Authors. Published by ESG (www.electrochemsci.org). This article is an open access article distributed under the terms and conditions of the Creative Commons Attribution license (http://creativecommons.org/licenses/by/4.0/). 